\title{
PONTO DE REFERÊNCIA: ANÁLISE TIPOLÓGICA DOS PRETÉRITOS MAIS-QUE-PERFEITO E PERFEITO DO INDICATIVO E IMPERFEITO DO SUBJUNTIVO*
}

\author{
Angela Cristina Di Palma BACK ${ }^{1}$ \\ Universidade do Extremo Sul Catarinense (UNESC) \\ Márluce COAN ${ }^{2}$ \\ Universidade Federal do Ceará (UFC)
}

\section{RESUMO}

Nossa proposta visa à análise do ponto de referência dos pretéritos perfeito e mais-queperfeito do indicativo e do pretérito imperfeito do subjuntivo, tempos verbais que apresentam contornos aspectuais e modais diferentes: os dois primeiros são perfectivos, realis; o último, imperfectivo, irrealis. As formas do indicativo, será aplicada tipologia que engloba ponto de referência semântico (temporal, discursivo e pressuposto) e ponto de referência pragmático (compartilhado), proposta ampliada na análise do imperfeito do subjuntivo: o ponto de referencia temporal passou a modo-temporal e os pontos discursivo e pressuposto foram considerados em relação ao tópico discursivo. Objetivamos, com esta pesquisa, mostrar que as formas verbais são interpretadas também em função de um atribuidor de referência (ponto de referência) que pode estar no contexto linguístico (atribuição de referência dada semanticamente) ou no contexto extralinguístico (atribuição de referência pragmática).

\footnotetext{
* Este artigo tem por base as pesquisas desenvolvidas por Coan (1997 e 2003) e Back (2008).

${ }^{1}$ Doutora em Linguística pela Universidade Federal de Santa Catarina e, atualmente, professora do Programa de Pós-Graduação em Educação da Universidade do Extremo Sul Catarinense e coordenadora do Grupo de Pesquisas LITTERA - Correlações entre cultura, processamento e ensino: a linguagem em foco.acb@unesc.net

${ }^{2}$ Doutora em Linguística pela Universidade Federal de Santa Catarina e, atualmente, professora do Programa de Pós-Graduação em Linguística da Universidade Federal do Ceará e coordenadora do Grupo de Pesquisas Sociolinguísticas -SOCIOLIN-CE. coanmalu@ufc.br
}

(C) Revista da ABRALIN, v.11, n.2, p. 11-41, jul./dez. 2012 
Ponto de Referência: Análise Tipológica dos Pretéritos Mais-Que Perfeito e Perfeito do Indicativo do Subjutivo

\section{ABSTRACT}

This article aims at analyzing the point of reference of the "pretérito perfeito" and "maisque-perfeito" of the indicative, and also the "pretérito imperfeito" of the subjunctive, verb tenses which present aspectual roles and modal differences: the former are perfective, realis; the latter, imperfective, irrealis. A typology that encompasses semantic (temporal, discursive, and assumed), and pragmatic (shared) points of reference will be applied to the indicative forms; this proposal is expanded in the analysis of the "imperfeito" of the subjunctive: the time point of reference has turned into time-mode, and the discursive and assumed were considered in relation to the discursive topic. This research wishes to demonstrate that verbal forms are also interpreted in terms of a reference ascriber (point of reference) that may be found either in the linguistic context (reference semantically ascribed) or in the extra-linguistic context (reference pragmatically ascribed).

\section{PALAVRAS-CHAVE}

Ponto de referência. Pretéritos perfeito e mais-que-perfeito do indicativo. Pretérito imperfeito do subjuntivo.

\section{KEYWORDS}

Point of reference. "Pretérito perfeito" and "mais-que-perfeito" of the indicative. "Pretérito imperfeito" of the subjunctive.

\section{Introdução}

Neste artigo, apresentamos, inicialmente, a noção de ponto de referência com base na proposta de Coan (2003), especificamente, conceito, estatuto e tipologia. Embora tal proposta tenha sido articulada para análise dos pretéritos mais-que-perfeito e perfeito do indicativo (formas perfectivas ${ }^{3}$, realis ${ }^{4}$ ), será aplicada à análise do pretérito imperfeito

\footnotetext{
${ }^{3}$ Aspecto refere-se ao modo como se vê a constituição temporal de uma situação: como um todo único sem distinção de fases (aspecto perfectivo) ou em sua constituição interna (aspecto imperfectivo), conforme atesta Comrie (1981, p.03).

${ }^{4}$ Givón (1984) faz referência aos seguintes tipos de modalidade: pressuposição (verdade por acordo prévio); asserção realis (algo é verdadeiro ou falso) e asserção irrealis (verdade possível).
} 
do subjuntivo, com o propósito de discutir possibilidades de alargamento teórico, ou seja, de responder à seguinte questão: a tipologia que serviu de análise aos pretéritos mais-que-perfeito e perfeito do indicativo pode servir ao pretérito imperfeito do subjuntivo, cuja configuração difere em termos modais e aspectuais?

Na primeira seção, apresentamos algumas considerações sobre ponto de referência (conceito, estatuto); na sequência (na seção dois), uma proposta tipológica: ponto de referência semântico (temporal, discursivo e pressuposto) e ponto de referência pragmático (compartilhado). $\mathrm{Na}$ última seção, essa proposta tipológica é aplicada ao imperfeito do subjuntivo, forma que codifica o aspecto imperfectivo e a modalidade irrealis; além disso, conforme Back (2008), no que se refere à expressão do tempo, tem caráter multifuncional, por codificar anterioridade, simultaneidade e posterioridade ao ponto de referência.

\section{Ponto de referência: algumas considerações ${ }^{5}$}

O tempo verbal, uma das estratégias linguísticas de codificação do tempo, pode ser descrito como a gramaticalização da relação entre o tempo de uma situação e o ponto zero do contexto dêitico - o momento da enunciação (LYONS, 1977), mas pode também ser descrito a partir da ancoragem em um outro tempo que não o tempo de fala (MATOS, 1996). Em enunciados descrevendo mais de um estado de coisas, a ordenação temporal é mais complexa, visto que os estados de coisas são ordenados relativamente ao momento de enunciação mas, para além disso, são ordenados uns relativamente aos outros (MATEUS et alii, 1983: 104-105).

O ponto de referência mais comum para a maioria das línguas parece ser o momento presente; existem, entretanto, casos que necessitam de algum outro ponto de referência (conforme COMRIE, 1990). Em Português, no eixo passado, a distância temporal em relação ao momento

${ }^{5}$ As considerações apresentadas nesta seção foram retiradas da seção 3.4 da tese de Coan (2003). 
Ponto de Referência: Análise Tipológica dos Pretéritos Mais-Que Perfeito e Perfeito do Indicativo do Subjutivo

da enunciação é assinalada por mecanismos como uso de expressões adverbiais (antes de, depois de...), tempo verbal (perfeito, mais-que-perfeito) e é possível, também, usar um verbo como acabar em acabo de chegar para indicar proximidade temporal ao presente. Embora o Português não tenha um sistema verbal para distanciamento tão produtivo quanto outras línguas ${ }^{6}$, é possível estabelecer subdivisões temporais devido a esses mecanismos e/ou ao nosso conhecimento de mundo.

A partir de certo ponto de referência (por exemplo, tempo verbal passado), uma forma verbal como o pretérito perfeito pode ser interpretada diferentemente do que seria se estivesse subordinada a outro ponto de referência (por exemplo, tempo verbal presente). Assim, objetivamos evidenciar que as formas verbais são interpretadas também em função de um atribuidor de referência que pode estar no contexto linguístico (atribuição de referência dada semanticamente) ou no contexto extralinguístico (atribuição de referência pragmática). A esse atribuidor de referência, chamamos de ponto de referência ${ }^{7}$, uma situação de ordem semântica ou pragmática à qual outra situação está vinculada.

Fleischman (1982) também se refere a uma caracterização mais pragmática de referência quando conceitua ponto de referência como um cenário ou plano temporal no qual um evento é localizado. Para tempos absolutos, o ponto de referência coincide com o tempo de fala,

\footnotetext{
${ }^{6}$ Existem sistemas temporais que apresentam mais de duas formas para fazer referência a subdivisões no passado: Kamba, Mabuiag, Bamileke-Dschang, Bamileke-Ngyemboom, Kiksht entre outros (conforme COMRIE, 1990). O Português apresenta os pretéritos perfeito e maisque-perfeito. $\mathrm{O}$ imperfeito não representa uma subdivisão em termos de distanciamento a partir do momento de fala: é um passado relativo ao momento de fala como o perfeito, diferenciandose deste aspectualmente: representa uma situação imperfectiva.

${ }^{7} \mathrm{Na}$ literatura linguística sobre referência, esse atribuidor tem sido nomeado como 'ponto' ou 'momento' de referência. Ilari (1997) vê a noção de 'momento' como problemática, e sugere usar termos como 'períodos' ou 'lapsos de tempo'. Ikeda (1992) fala em 'âncora', ao tratar do imperfeito que, normalmente, ocorre com outra situação cotemporal. Desde que devidamente caracterizada, não nos parece problemática a noção de 'ponto de referência'. Note-se que, em se tratando de referência espacial, quando alguém solicita um ponto de referência, este pode ser uma placa, um edifício, uma praia, uma cidade, entre outros.
} 
enquanto para relativos, funcionará como um portão para o tempo de fala. Esse cenário envolve advérbios, verbos, expressões nominais, o contexto. Comrie (1990) estabelece o momento de fala como centro dêitico; assim, três tempos verbais básicos formam a espinha dorsal da referência temporal em gramática: presente, passado e futuro, chamados de tempos verbais absolutos em oposição aos relativos e relativoabsolutos. Tempos verbais relativos têm algum outro ponto no tempo, dado pelo contexto, como ponto de referência. Tempos verbais relativoabsolutos combinam localização de tempo absoluto de um ponto de referência com localização de tempo relativo de uma situação. A existência de tempo verbal relativo-absoluto decorre da existência de um ponto de referência antes ou depois do momento de fala e da localização da situação anterior, simultânea ou posteriormente a esse ponto.

Nessa mesma linha de raciocínio, Matos $(1996)^{8}$ considera que a referência pode não estar explicitada no discurso. Mas se não estiver, deve ser possível reconstituí-la com base em conhecimentos comuns ou por meio de cadeias de associações regulares ou dedutíveis do contexto. Vejamos:

(1) ERA o vento. (op. cit., pág.458)

(Contexto: ouve-se um barulho no sótão. O marido vai inspecionar e ao voltar diz: Era o vento.)

De acordo com Givón (1993), o ponto de referência mais comum nas línguas é o tempo de fala, ancorado no ato de fala e admitido como um tempo não-marcado (cf. diagrama abaixo). Nesse sentido, Givón, como Lyons (1977), vê o tempo verbal como parte de um frame (modelo/ cenário/plano) dêitico de referência temporal que gramaticaliza a relação entre o tempo da situação e o ponto zero temporal do contexto dêitico (momento de fala). Além de focalizar o momento de fala, Givón (1984) vê outras possibilidades de ligação entre os eventos, no sentido

${ }^{8}$ Com base em Tasmowski-de Ryck (1985) e Vetters (1993). 
Ponto de Referência: Análise Tipológica dos Pretéritos Mais-Que Perfeito e Perfeito do Indicativo do Subjutivo

de a referência estar acoplada à relevância, assim, se algum evento é mencionado dentro do discurso, fora de sequência, é porque ele é de algum modo relevante para aquele último ponto do discurso.

Ponto de referência:

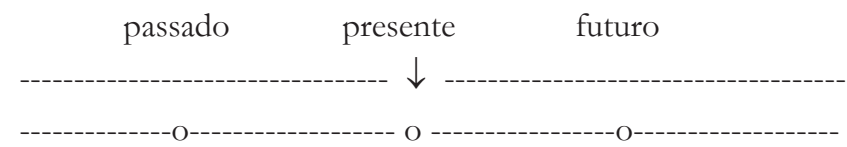

ponto de referência/tempo de fala

Situações no passado, no presente e no futuro, vinculadas ao tempo de fala, tomam esse tempo como ponto de referência. Mas é possível que uma situação que tenha como ponto de referência o tempo de fala possa constituir-se ela mesma em ponto de referência para outra situação que lhe é anterior ou posterior (tempo relativo-absoluto, nos termos de COMRIE, 1990).

Se a situação estiver no mesmo ponto da linha temporal onde está o tempo de fala, esse tempo é o ponto de referência e a situação codificada deve ser um tipo de reportagem imediata, ou seja, deve ocorrer exatamente no momento do ato da fala:

(2) Rubinho ATRAVESSA a linha de chegada. (ato de fala)

Para caracterizar situações na linha temporal, pode-se utilizar a estrutura de três pontos apresentada por Reichenbach (1947)': evento (E), referência (R) e momento de fala $(\mathrm{F})$. A título de ilustração, vejamos o diagrama proposto para o past perfect (pretérito mais-que-perfeito):

\footnotetext{
${ }^{9}$ O esquema de três pontos apresentado por Reichenbach (1947) foi originariamente proposto por Jespersen. In: JESPERSEN, J. O. H. The Philosophy of Grammar, H. Holt, New York, 1924.
} 
Diagrama temporal para o past perfect, conforme Reichenbach (op.cit.):

Nossa proposta para referência temporal (pontos de referência semânticos e/ou pragmáticos) pauta-se na referência espacial. Quando desejamos chegar a algum lugar, normalmente, temos indicadores, "pontos de referência" que são calculados para uma melhor localização espacial. Esses "pontos" podem ser dados pelo interlocutor ou chegamos ao local desejado porque temos referências armazenadas em nossa memória (conhecimento de mundo). Assim, ocorre na interpretação temporal. Calculamos o tempo verbal mais o(s) ponto(s) de referência e chegamos à interpretação desejada. Pode ser o caso de um ponto ou um período estar em jogo, mas esse é um problema aspectual do atribuidor de referência. Assim, nem sempre é um ponto que serve como referência (uma forma verbal, por exemplo), há atribuidores de referência tanto em nível textual quando contextual. Esses atribuidores ocupam o ponto R do diagrama de Reichenbach (1947), mas essa posição pode ficar aparentemente vazia (em termos de codificação), se o ponto de referência for de natureza pragmática (conhecimento de mundo).

A seguir, essa proposta será melhor explicitada: trataremos de ponto de referência de natureza semântica e de ponto de referência de natureza pragmática.

\section{Ponto de referência: proposta tipológica ${ }^{10}$}

Classificamos os pontos de referência em dois tipos: os localizados

\footnotetext{
${ }^{10}$ As considerações apresentadas nesta seção foram retiradas da subseção 3.4 .1 da tese de Coan (2003). A tipologia aqui utilizada foi configurada a partir da análise dos dados, visando, especificamente, a detalhar os tipos de ponto de referência. Não se trata aqui de julgamento de valor em relação a esta e outras propostas que lidam com ponto de referência, tais como Bello (1841), Reichenbach (1947), Comrie (1990) e Rojo \& Veiga (1999). Nosso objetivo foi a aplicação ao pretérito imperfeito de uma proposta articulada para os pretéritos perfeito e maisque-perfeito.
} 
Ponto de Referência: Análise Tipológica dos Pretéritos Mais-Que Perfeito e Perfeito do Indicativo do Subjutivo

no contexto semântico (unidades linguísticas) e os localizados no contexto pragmático (atribuidores dados extra-textualmente).

Dado que a semântica estuda os aspectos do significado codificados em expressões linguísticas, o sentido convencional, o contexto semântico é o contexto de ordem linguística, um contexto que se "materializa" no ato da comunicação. Mas, de acordo com Sperber e Wilson (1995), a linguagem externa nem sempre codifica o tipo de informação que os humanos estão interessados em codificar. As representações semânticas codificadas são estruturas mentais abstratas que devem ser inferencialmente enriquecidas.

Assim, a pragmática, num olhar além, lida com a intenção e com o conhecimento que falante e ouvinte compartilham (implicitamente). $\mathrm{O}$ contexto pragmático é, então, constituído pelo conjunto de informações (conhecimento de mundo e da situação, crenças) não verbalizadas, mas partilhadas por falante e ouvinte, e inferidas no ato da comunicação. "Os contextos que não dependem dessa atribuição de crenças não são pragmáticos, mas definidos no componente semântico, em função da dinâmica do discurso" (conforme MOURA, 1999: 76). Contudo, convém ressaltar que “a compreensão pragmática se dá paralelamente ao processo relativo de compreensão semântica, no qual os discursos e conhecimentos prévios do contexto são importantes para a interpretação de cada sentença." (VAN DIJK,1992: 81).

A importância de se lidar também com o contexto pragmático é evitar um tipo de falha interpretativa que ocorre, às vezes, quando se leva em conta apenas o contexto semântico. Quando o componente linguístico indica que mais de uma interpretação é possível, a solução interpretativa deve estar na pragmática. O problema é que nem sempre falante e ouvinte partilham do mesmo contexto pragmático, ou o falante não sabe que não partilham. Se não há informação contextual suficiente, ambiguidades podem não ser solucionadas. 
A seguir, trataremos de ponto de referência de natureza semântica (temporal, discursivo e pressuposto) e de ponto de referência pragmático (compartilhado).

\subsection{Ponto de referência semântico}

A interpretação dos pretéritos mais-que-perfeito e perfeito decorre, na maioria dos casos, da existência de um ponto de referência semântico, mas nem sempre é o mesmo tipo que está em jogo. Vejamos alguns casos: temporal, discursivo e pressuposto.

\subsubsection{Ponto de referência temporal}

O ponto de referência temporal pode ocorrer expresso por verbo ou advérbio. Utilizamos basicamente dois critérios para a identificação do ponto de referência verbal (ilustrado em (03)): a relevância semânticosintática e o princípio da proximidade. Givón (1984) destaca o papel da relevância ao tratar de eventos contrassequenciais: se algum evento é mencionado no discurso fora da sequência discursiva, isso se deve ao fato de o evento ser relevante para o último ponto apresentado no discurso precedente.

Também o princípio da proximidade, proposto por Givón (1991b: 89), é pertinente nessa análise:

Entidades que estão mais próximas funcional, conceptual ou cognitivamente serão colocadas mais próximas no nível da codificação, i.é, temporal ou espacialmente.

Operadores serão colocados mais próximos, temporal ou espacialmente no nível da codificação, da unidade conceptual para a qual forem mais relevantes. 
(3) Eu adorava, que eu sou gordinha, né? adorava um suquinho, [um negócio] comer, né? Então, quando eles não queriam dar pra mim, quer dizer, o suco, né? aí, eu dizia que eu ia contar para o meu pai que eles TINHAM me BATIDO... (FLP 01,

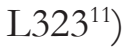

E

$\mathrm{R}$

$\mathrm{F}$

TINHAM BATIDO

ia contar

As situações codificadas por tinham batido e ia contar estão dispostas, no diagrama, em ordem cronológica, na ordem em que ocorreram, embora sejam, no discurso, codificadas contrassequencialmente. O evento tinham batido ancora-se ia contar, que é seu ponto de referência, visto que está próximo da situação codificada pelo pretérito mais-queperfeito composto, sendo esta relevante para o discurso anterior: ia contar. Note-se que ambas as situações também têm como ponto de referência o momento de fala. Trata-se, aqui, de situações relativo-absolutas, nos termos de Comrie (1990), ou seja, situações que, embora vinculadas ao momento de fala, também o são a outro ponto da sequência discursiva: tinham batido tem ia contar como ponto de referência que, por sua vez, tem dizia como ponto de referência.

Os advérbios podem servir como ponto de referência em dois sentidos: como indicadores de que a forma verbal em foco deve ser interpretada como anterior ou posterior; ou como especificadores do tempo codificado por essa forma verbal. Vejamos como isso ocorre:

(4) John HAD already LEFT at ten o'clock. João já TINHA SAÍDO às dez horas.

\footnotetext{
${ }^{11}$ Exemplos com essa configuração foram retirados de entrevistas do Projeto VARSUL. FLP refere-se a Florianópolis, 01 refere-se ao número da entrevista e L323, ao número da linha.
} 
A expressão adverbial às dez horas pode ser o ponto de referência, se a partida de John for anterior às dez horas. Em português, essa seria a interpretação pretendida por causa da inserção do advérbio já (already). Entretanto, a expressão adverbial às dez horas também pode expressar o momento da partida de John (conforme COMRIE, 1990). Neste caso, para o autor, a presença do advérbio conduz à existência de dupla referência: tinha saído pode ser interpretado como anterior ou simultâneo à expressão às dez horas. O mesmo pode ser verificado em (5):

(5) Em 1940, o fenômeno dos raios cósmicos já TINHA SIDO REGISTRADO várias vezes. (ILARI, 1997:18)

Em 1940 (no exemplo acima) pode ser interpretado, indiferentemente, como o tempo da situação (tinha sido registrado) ou como posterior a essa situação: o fenômeno dos raios cósmicos pode ter sido registrado várias vezes antes de 1940 ou várias vezes em 1940. Nesses casos, há que se recorrer ao contexto discursivo ou situacional.

Há, entretanto, casos em que essa dupla interpretação não ocorre. Em (6), a expressão adverbial (no quarto dia) funciona como ponto de referência temporalmente posterior à situação sob análise, ou seja, $a$ barriga voltou ao normal antes do quarto dia.

(6) Bem, voltei lá pro hospital e durante um, dois, três, no quarto dia, a menina já TINHA VOLTADO a barriga, ao normal, já estava evacuando normalmente, e foi indo, foi indo, até que ela saiu do hospital. (FLP 23, L1288)

\subsubsection{Ponto de referência discursivo}

Nos casos de retomada discursiva, o ponto de referência pode ser percebido no contexto linguístico anterior ou seguinte ao dado. Observese o exemplo: 
7) Correr, eu correr, Deus me livre!... Então, sempre me escondia lá. Sempre me escondia nessas horas de correr, de fazer ginástica. (FLP 01, L332)

Correr, como já FALEI, não corria, não corria. (L368)

Percebemos que a forma verbal falei, na retomada acima, pode ser substituída por uma forma de pretérito mais-que-perfeito. Em qualquer dos casos (perfeito ou mais-que-perfeito), o que está em jogo é a retomada, que tem sua primeira menção recuperável no contexto discursivo precedente.

\subsubsection{Ponto de referência pressuposto}

Considere-se o seguinte exemplo:

(8) Eu sei que um filme de bandido mesmo, que eu nunca VI matar tanto. (FLP 05, L236)

No exemplo acima, a presença do intensificador tanto informa que a negação de $v i$ se sustenta apenas até a ocorrência do filme. Logo, o pretérito perfeito $(v)$ tem o mesmo significado do pretérito mais-queperfeito (tinha visto). O falante viu matar (antes do tempo de fala), mas até então (até o filme) não tinha visto matar tanto.

Note-se que aqui o tanto introduz um pressuposto que era válido também no passado (viu matar). O nunca não nega esse pressuposto, mas a intensidade do matar. Não nega o ver, mas o tanto. Mas em:

(9) Eu nunca VI isso...

pode-se perguntar: viu ou não viu? Se se leva em conta apenas o contexto semântico, esse enunciado é ambíguo. Parece que há um ponto em que a interpretação adequada só é possível se se extrapola o nível semântico. 
Por outro lado, a utilização do pretérito mais-que-perfeito juntamente com uma expressão adverbial de negação possibilita a interpretação dessa mesma situação como tendo ocorrido em um passado posterior (conforme exemplo 10). O passado posterior pressuposto ( $v i$ é o que consideramos como ponto de referência para nunca tinha visto. Mas isso não vale para os casos de pretérito perfeito, pois a inferência não depende unicamente da forma verbal, é necessário também um apoio contextual, que pode ser semântico ou pragmático, como será exposto na próxima subseção. O pretérito perfeito (em 9) somente será interpretado como um tempo passado anterior se o contexto favorecer tal interpretação.

(10) Eu nunca TINHA VISTO isso...

\subsection{Ponto de referência pragmático}

Seguindo a tradição lógica, caberia à semântica explicitar como a referência é determinada. Em muitos casos, entretanto, não se pode determinar a referência se não se leva em conta o contexto pragmático. Quando a identificação da significação não se dá linguisticamente, passa pela determinação do que é comum ao conjunto de falantes (conforme MOURA, 1999). Isso quer dizer que, além do contexto semântico, é possível recorrer a outros elementos: intenção, contexto situacional, conhecimento de mundo. A chave para a interpretação de algumas formas verbais pode estar nessa atribuição de referência dada pragmaticamente.

Em casos com o advérbio nunca, pode-se considerar a existência de um ponto de referência compartilhado. Vejamos:

(11) Nunca TIREI mais do que seis em Matemática.

Quando o pretérito mais-que-perfeito está relacionado ao advérbio nunca, há uma inferência (afirmação implícita de uma situação contrária): 
Ponto de Referência: Análise Tipológica dos Pretéritos Mais-Que Perfeito e Perfeito do Indicativo do Subjutivo

nunca tinha tirado implica tirar num passado posterior. Essa inferência permite a existência de uma relação entre três termos, respectivamente, o tempo de fala, um passado (ponto de referência inferível) e um passado anterior. Isso, entretanto, nem sempre acontece com o pretérito perfeito. Para o exemplo acima, há duas interpretações possíveis:

(11a) Não TIREI mais do que seis em Matemática.

(11b) TIREI mais do que seis em Matemática.

Quando um ponto de referência não é dado no contexto semântico, como acontece nesse caso, pode-se dizer que tirei é um pretérito perfeito simples e a interpretação é aquela em (11a), mas é possível, também, considerar um ponto de referência no sentido pragmático e dizer que tirei equivale a tinha tirado (interpretação dada em 11b). Como somos capazes, então, de interpretar corretamente o enunciado (11)? Se levarmos em conta apenas o contexto semântico, temos uma situação (tirę) negada até o tempo de fala. Sabendo, porém, que a pessoa tirou oito na última avaliação de Matemática, esse enunciado seria falso. Assim, para se interpretar tirei como tinha tirado, ou seja, para considerar esse enunciado como verdadeiro, é preciso recorrer ao contexto pragmático. O falante, possivelmente, usa tirei querendo dizer tinha tirado, porque presume que seu interlocutor sabe sobre a nota da última avaliação. Note-se, contudo, que para quem não sabe o resultado da avaliação, a negação se sustenta até o tempo de fala.

Implicaturas, segundo Grice (1975), são revogáveis, ou seja, é possível anular uma interpretação, se premissas puderem ser acrescidas às originais. ${ }^{12}$ No enunciado abaixo, por exemplo, o significado de $v i$ é recuperável cataforicamente. Note-se, contudo, que, com a primeira oração apenas, vi é ambíguo.

\footnotetext{
${ }^{12}$ Essas premissas permitem um alargamento do ambiente cognitivo (nos termos de SPERBER; WILSON, 1995).
} 
(12) Copa do mundo, eu nunca VI. O Brasil ser campeão da Copa do Mundo só fui ver o ano passado. (FLP, Leda/10)

Pinkal (1995: 81, apud Moura, 1999: 79-80) chama de precisificação essa outra maneira de resolver ambiguidades: "uma precisificação fornece um contexto mais informativo no qual a ambiguidade é eliminada, nesse caso, a resolução depende da dinâmica do discurso." No entanto, em muitos casos, para a identificação de um referente, deve-se recorrer ao componente pragmático (conhecimento compartilhado, crenças). Um falante usa x (uma expressão linguística qualquer) porque acredita que seu interlocutor será capaz de identificar x (Princípio da Cooperação - GRICE, 1975). Isso significa que o falante de x está respeitando a máxima da maneira proposta por Grice ("evite ambiguidade”), pois se há conhecimento compartilhado, não há ambiguidade. A ambiguidade resulta do fato de o ouvinte não ter o conhecimento que o falante atribui a ele indevidamente. Mas se se leva em conta a pragmática, como um domínio contextual ${ }^{13}$, reduzem-se, consideravelmente, os casos de ambiguidade.

\section{Pontos de referência do pretérito imperfeito do subjuntivo - outros lugares no e para além do discurso ${ }^{14}$}

Podemos dizer que, para a análise do pretérito imperfeito do subjuntivo (doravante PIS), a proposta de Coan (2003) pode ganhar inovações, sobretudo em se tratando do domínio semântico, mais

\footnotetext{
${ }^{13}$ Pode-se incluir, nesta etapa, a noção de domínio contextual, proposta por McCawley (1993), não unicamente no sentido de um conjunto de entidades cujas identidades se constituem como conhecimento partilhado por falante e ouvinte, mas no sentido de informações partilhadas. Assim, se falante e ouvinte têm domínios contextuais em comum, a ambiguidade deve ser algo raro. McCawley, J. Everything that linguistics have always wanted to know about logic. Chicago: University of Chicago Press, 1983.

${ }^{14}$ As considerações apresentadas nesta seção resultam de discussões teóricas e de resultados da tese de Back (2008).
} 
Ponto de Referência: Análise Tipológica dos Pretéritos Mais-Que Perfeito e Perfeito do Indicativo do Subjutivo

especificamente para os pontos de referência discursivo e pressuposto, pois os dados do PIS, analisados sob esses parâmetros, suscitaram refinamentos metodológicos. Com relação ao ponto de referência pressuposto, houve dúvidas acerca da dimensão da atribuição temporal: se estaria no domínio semântico ou pragmático; já em se tratando do ponto de referência discursivo, tivemos que operar com a noção de tópico como unidade de análise, a partir do qual se delimitaram as entrevistas em seções temáticas. As ocorrências do PIS são do banco de dados Entrevistas Sociolinguisticas da UNESC (Universidade do Extremo Sul Catarinense), idealizado nos mesmos moldes do VARSUL ${ }^{15}$.

Podemos dizer que a proposta também pode ser expandida, pois, para o PIS, fica em evidência a Modalidade, categoria a partir da qual se explica, por exemplo, por que situações negadas, chamadas por GIVÓN (2001; 2005) de asserções-NEG, apresentam-se com valores ora de passado ora de presente. Trata-se de levar em consideração as pistas modais presentes na situação sociocomunicativa, adicionando mais elementos à noção de ponto de referência, ou seja, levar em consideração que a Modalidade compreende a atitude tomada (modus) pelo falante em face do conteúdo (dictum) que enuncia (DUCROT, 1972, p. 368) e que essa atitude, nas diferentes línguas, pode, além de ser gramaticalmente marcada (LYONS, 1979, p. 324), também envolver crenças, conbecimento de mundo, expressando, por exemplo, (in) certeza subjetiva, marcada, por vezes, no nível estrutural da língua, outras no nível discursivo-pragmático.

Para operacionalizar essas noções compósitas e recursivas que envolvem a manifestação do ponto de referência, Coan $(2003)^{16}$ sistematiza os lugares nos quais podem estar esses pontos, propondo

\footnotetext{
${ }^{15}$ Variação Linguística Urbana na Região Sul do Brasil - Projeto interinstitucional que agrega as seguintes universidades: UFPR, UFSC, UFRGS e PUC-RS. O corpus do Banco de Entrevistas Sociolinguísticas da UNESC compõe-se de sessenta entrevistas sociolinguísticas realizadas no município de Criciúma/SC, em 2001 (ano da coleta), com informantes da área urbana, distribuídos de forma homogênea em relação às células sociais: sexo, idade e escolaridade. Tratase, portanto, de uma amostra sincrônica.

${ }^{16}$ A exemplo de Coan (2003), Freitag (2007) também trata do ponto de referência considerando dimensões para além das estruturas linguísticas.
} 
uma tipologia que compreende não só a localização estrutural, mas avança para além dela. A autora busca interpretações para a localização do ponto de referência das formas verbais no contexto linguístico (dimensão semântica) e no extralinguístico (dimensão pragmática).

Isso posto, passemos a uma breve discussão sobre a unidade de análise: tópico discursivo e, a posteriori, à análise de algumas ocorrências com o propósito de concretizar os encaminhamentos teóricos até aqui discutidos.

\subsection{Unidade de análise: tópico discursivo}

Back (2008) observa que a entrevista sociolinguística é, por vezes, vista como constituída de relatos eminentemente de experiência pessoal, em que os informantes tentam resgatar as experiências mais importantes de suas vidas, não elaborando, portanto, experiências de outros. Entendese que a elicitação de narrativas que envolvem questões sobre a vida e a morte coloca em evidência habilidades que são acionadas visando a apresentar as situações de modo mais casual, bem humorado ou mesmo como se fossem assuntos triviais que fazem parte do cotidiano. Esse modo de reportar experiências revela uma propriedade que define a narrativa de experiência pessoal: eventos são narrados como se fossem novamente experienciados. Labov e Waletzky (1967) definem narrativa como a técnica de reportar eventos passados por meio da juntura temporal. Para Labov (1997), o evento mais reportável funciona como o pivô semântico e estrutural a partir do qual a narrativa se organiza, de modo que a narrativa pode ser vista como aquela que, estruturalmente, possui um evento mais reportável. Com base nisso, podemos dizer que a estratégia de localizar o tema equivale a localizar o evento mais reportável.

A reflexão de Labov e Waletzky (op. cit.), segundo Back (2008), foi um desdobramento dos métodos desenvolvidos no trabalho de Labov (1966) junto à comunidade do Harlem. Pode-se dizer que as 
Ponto de Referência: Análise Tipológica dos Pretéritos Mais-Que Perfeito e Perfeito do Indicativo do Subjutivo

considerações desses autores se constituem como um marco a partir do qual somos levados a entender a estrutura da narrativa e como ela se apresenta na conversação cotidiana, estrutura que tende a ocorrer, segundo Labov (1997), em narrativas de um modo geral. Valemonos desses procedimentos metodológicos, estendendo-os a unidades temáticas que se constituem como tópicos na organização discursiva das entrevistas sociolinguísticas.

Labov e Walestzky (1967) defendem a existência de níveis estruturais ${ }^{17}$ que compõem a narrativa, e, com base nessa discussão, foi possível antever em que partes poderia aparecer o PIS: em passagens nas quais se observa suspensão temporal. Segundo Back (2008), um dos motivos para isso é justamente a modalização, sobretudo no que se refere à avaliação. Para a autora, se a narrativa requer que os relatos reportem eventos reais (modalidade realis), é esperado que o PIS, característico de modalidade irrealis, não sirva como núcleo temporal. Portanto, não devendo figurar nas junturas temporais.

Back (2008) observa ser justamente no limite entre a complicação e o resultado, dois dos níveis estruturais da subdivisão proposta por Labov e Walestzky (1967), que se verificam, predominantemente, as avaliações nas quais se presenciam estruturas que suspendem a sequência temporal. E isso se faz, via de regra, por meio de modais, de negação ou, ainda, de projeções futuras, construções que comportam o PIS. Essa discussão é fundamental para os critérios metodológicos já que, na entrevista sociolinguística, lidamos com sequências temáticas nas quais há a presença de opiniões, projeções com cargas avaliativas.

A delimitação da entrevista sociolinguística em tópicos, ou, melhor dizendo, a segmentação em excertos temáticos menores, inspira-se no trabalho de Gorski (1994), para quem o mecanismo de explicitação de tópicos e subtópicos é um auxiliar produtivo na tarefa de segmentação do discurso em suas partes constitutivas (p. 79). Vejamos a ocorrência seguinte:

\footnotetext{
${ }^{17}$ Resumo, orientação, complicação, avaliação, resolução e coda.
} 
(13)

$\mathrm{E} *$ Como eram os bailes? ${ }^{18}$

$\mathrm{F}^{*} \mathrm{Ah}$, os bailes, era assim ó, vou contar pra vocês, vocês vão rir, a gente estava sentada assim, e os moços do outro lado, eles vinham convidar a gente pra dançar, a gente ia dançar, na outra eles vinha de novo, se a gente DISSESSE que não ia dançar, eles marcavam, aí se VIESSE outro moço, às vezes, tem moço que a gente não quer dançar, né? *Se VIESSE outro moço, te CONVIDASSE pra dançar e tu ias dançar com o outro moço, aquele que tu não foste, que tu negaste, ia lá reclamar pro dono do salão, aí tu não dançavas mais. *Era assim. (SCCRI08, p. $2^{19}$ )

A ocorrência acima apresenta começo, meio e fim; e o tópico discursivo pode ser nomeado como "Os bailes da minha juventude - éramos obrigadas a dançar”. Nele, observa-se a apresentação dos personagens (a gente, os moços), logo em seguida se dá a sequência de eventos em se tratando de os moços convidarem as moças para dançar. Ainda na sequência, na complicação, há uma situação contrafactual que se mostra hipotético-avaliativa - se a gente dissesse que não ia dançar, eles marcavam o que revela uma espécie de parada na ação sequencial em função de a situação apresentar-se como possível e não como fato, criando uma realidade alternativa hipotética. Por fim, há a finalização - Era assim.

A orientação metodológica, aqui, é similar à de Gorski (op. cit.) quanto à delimitação dos tópicos com base no critério de mudança de cenário, no qual se observa a (re)orientação em termos de localização espaço-temporal. O encaminhamento para a delimitação do tópico deuse na seguinte ordem: 1) localizou-se a ocorrência com o PIS; 2) buscouse o evento mais reportável ou aquele que se colocasse em evidência e que pudesse ser desencadeado a partir da pergunta do entrevistador; 3 ) recortou-se, com o auxílio da orientação do cenário, o tópico discursivo

\footnotetext{
${ }^{18}$ Os asteriscos chamam atenção para o enunciador, focalizando a mudança de turno entre entrevistador e informante.

${ }^{19}$ SC refere-se ao estado de Santa Catarina, CRI refere-se ao município de Criciúma e 08, p.2, respectivamente, ao número da entrevista e à página.
} 
Ponto de Referência: Análise Tipológica dos Pretéritos Mais-Que Perfeito e Perfeito do Indicativo do Subjutivo

que recobriu (1) e (2). Essa delimitação se constituiu na unidade de análise semântico-discursiva na qual as evidências com o PIS passaram a ser consideradas.

Gorski (op. cit.) observa que, embora a função básica na narrativa seja a de encaminhar cronologicamente as ações, os eventos podem também corresponder a ações que dão continuidade ao fluxo discursivo, mas que não avançam temporalmente o relato; e podem ainda consistir em estados ou situações descritivas que acompanham em segundo plano o desenrolar das ações, funcionando, assim, como as unidades não-narrativas de Labov e Waletzky (1967), justamente os contextos apropriados à realização de PIS.

\subsection{Ponto de referência: operacionalização}

Compreender que o ponto de referência pode ser buscado, inclusive, pragmaticamente foi importante por nos depararmos com uma forma -sse a serviço de variados Tempos e que, por assim dizer, comporta modalizações que, muitas vezes, acabam por obscurecer a própria função temporal. O mapeamento funcional do PIS dentro desse universo de intensa modalização, cujo ponto de referência se localiza ora no discurso ora para além dele, proporcionou a Back (2008) arrolar sete esquemas temporais ${ }^{20}$. Para interpretar os esquemas, tivemos, em certa medida, que lidar com traços modais permeados de certeza subjetiva, possibilidade, condicionalidade e hipoteticidade, daí a proposta de Coan (2003) mostrarse com alto poder explicativo em análises dessa natureza. A ocorrência a seguir se realiza no âmbito de uma oração relativa. Vejamos como podemos interpretá-la segundo sua constituição temporal.

(14) Quando a gente, de vez em quando escutava, calcava o peso lá pra trás e (inint) acarcava e faz̧ia aquela quebraçada ("pra dizer") que nós fazíamos uma taipa, que era obrigado a fazer uma

\footnotetext{
${ }^{20}$ Esquemas temporais para o PIS: 1) antepretérito, 2) copretérito, 3) pós-pretérito, 4) presente, 5) antefuturo, 6) futuro e 7) pós-futuro. Essa terminologia, para rotular os tempos verbais, é de Bello ([1841] 1979; [1847] 1984). Para maiores detalhes, ver Back (2008).
} 
taipa que ENCOSTASSE até no teto, uma taipa de pedra, da própria frente, né?* Então encostava até assim no teto, só deixava um corredor pelo meio, né? (SCCRI01, p. 5)

Assumimos que a ocorrência acima expressa o que chamamos de póspretérito, cujo valor é de futuro do passado. Muito embora Reichenbach não aborde formas verbais como a expressa em (14), a constituição temporal desse dado pode ser depreendida dos diagramas que o autor propõe, fazendo uso de sua lógica temporal. Tomemos, como ponto de partida, sua proposta para o past perfect do inglês, que se configura como passado do passado: o momento de referência é uma situação posterior ao past perfect, mas anterior ao ponto de fala. De modo aproximado, em (14), o ponto de referência é uma situação anterior ao PIS, sendo ambas anteriores ao momento de fala. Faz-se, portanto, a análise com base no cálculo que considera os três pontos na linha do tempo (evento, referência e momento de fala).

Vale, ainda, um registro importante com relação à ocorrência (14), em se tratando da complexidade estrutural da construção era obrigado a fazer. Estamos considerando esse todo composicional como ponto de referência por duas razões, sendo a segunda decorrente parcialmente da primeira: (i) fazer se apreende na estrutura como tempo relativo ${ }^{21}$ (COMRIE, 1990), que capta o sentido temporal de outro verbo, no caso, do pretérito imperfeito era, atuando em conjunto como referência para encostasse; (ii) o bloco era obrigado a fazerer recebe uma interpretação de Modalidade, focalizando a obrigação deôntica, cujo sentido equivale a ter que fazer ou, ainda, devia fazer, que acaba por se sobrepor ao valor temporal, tomando os dois verbos como um todo realizado sob a forma temporal imperfectiva de passado.

\footnotetext{
${ }^{21}$ Segundo Comrie (1990), há os tempos verbais absolutos e os relativos. Os absolutos têm o momento de fala como ponto de referência. Já para interpretar os tempos verbais relativos, há que se levar em consideração não só o momento presente, como também e, por vezes, somente outro ponto no tempo, dado pelo contexto, como ponto de referência.
} 
Ponto de Referência: Análise Tipológica dos Pretéritos Mais-Que Perfeito e Perfeito do Indicativo do Subjutivo

Em suma, em (14), o PIS se realiza, estruturalmente, de forma encaixada, e ocorre, do ponto de vista cronológico, imediatamente posterior ao MR ao qual está correlacionado. Nesse caso, era obrigado a fazer, naquele contexto, assume o valor temporal de passado e torna-se o ponto de referência para encostasse, o qual possui valor temporal de póspretérito (futuro do passado). Vale ressaltar que, na ocorrência (14), não se vê cotemporalidade, ou seja, enquanto se está fazendo a taipa, ela, por consequência, ainda não encosta no telhado; terminada a taipa, então ela encosta no telhado. Assim, o pós-pretérito representa o valor temporal de uma situação que é posterior a outra no passado, fórmula já prevista para o castelhano por Bello ([1841] 1979; [1847] 1984) em se tratando de - sse.

Um ponto que gostaríamos ainda de destacar diz respeito a uma particularidade que diferencia propostas como a de Bello, por exemplo, da de Reichenbach (1947): trata-se do uso de evidências reais. Ao fazer isso, Bello acaba verificando empiricamente que algumas formas assumem outros valores, a exemplo do que atestamos para a forma -sse. Algumas evidências mostram que a forma não necessariamente focaliza o tempo. A esse respeito, Back (2007), com fundamentos em Bello (op. cit.), apresentou, como valores metafóricos para o PIS, negação indireta, condição exclusiva e falsa condição. Ratifica-se, portanto, uma análise que premia o olhar funcionalista, que observa a expressão do tempo no contexto discursivo ou pragmático.

A título de ilustração, tomemos uma ocorrência de Back (2007) ${ }^{22} \mathrm{em}$ que o foco não é a temporalidade, mas sim o valor metafórico de condição exclusiva:

(15) ... Brincadeira de jogar no buraco, tinha brincadeira de jogar no buraco. Tinha que pular o buraco, quem não PULASSE tinha que ser jogado no buraco. E eu sempre era jogada dentro do buraco, né? e ficava lá.... [VAFL01]

\footnotetext{
${ }^{22}$ Para maiores informações sobre valores metafóricos do PIS, sugerimos a leitura de Back (2007).
} 
Back (2008) analisa a forma pulasse com valor metafórico, tomando como referência a forma tinha que ser jogado. Segundo a autora, como o ato de pular é anterior ao de ser jogado, a negação de um dos pares é a afirmação de outro. A negação em jogo explicita o sentido de exclusão de uma das ações (Se pular, não é jogado ou Se não pular, é jogado). Essa exclusão associada à negação é o que a autora passa a chamar de negação exclusiva. É possível perceber que não se trata da temporalidade em jogo, haja vista que a interpretação requer que se desloque a situação reportada como um presente do passado caracterizado pelo matiz aspectual imperfectivo da forma _sse. Contudo, ressalta-se que não se trata de coexistência pretérita, haja vista que não pular é anterior a ser jogado, daí serem mutuamente exclusivos.

(15) ilustra justamente como as formas dão visibilidade, às vezes, à modalização, obscurecendo a temporalidade. Portanto, voltando ao dado (14), o valor modal que se apresenta é deôntico, de modo que poderíamos classificar o ponto de referência como modo-temporal. Temos evidências, então, de que o ponto de referência não pode ser entendido apenas como temporal, mas como modo-temporal.

O próximo dado requer interpretação para além do escopo oracional, embora, aparentemente, a referência esteja explicitada. Vejamos (16):

(16) Meu pai não queria que nós NAMORÁSSEMOS [...] (SCCRI01, p. 08)

A função temporal de PIS, em (16), só pode ser atestada buscando seu ponto de referência discursivamente, uma vez que o recorte não possibilita saber qual das situações ocorre primeiro do ponto de vista cronológico, constituindo-se numa situação polissêmica quanto a sua função temporal. Assim, podemos observar que, do ponto de vista estrutural, não nos é possível determinar, sem o auxílio de outras pistas ${ }^{23}$, se o ponto de referência (queria) é anterior, simultâneo ou posterior a namorássemos.

${ }^{23}$ Rojo \& Veiga (1999: 2869-2933) propõem um sistema temporal altamente recursivo por meio do qual consideram variadas pistas linguísticas que chamam de referências secundárias. 
Ponto de Referência: Análise Tipológica dos Pretéritos Mais-Que Perfeito e Perfeito do Indicativo do Subjutivo

A primeira análise encerra uma interpretação de que o casal ainda não namorava e o pai, de antemão, já observando o que poderia vir a ser, não queria $[\mathrm{R}-\mathrm{E}-\mathrm{F}]$. A segunda interpretação pressupõe a situação de que o casal já namorava e o pai, ao saber disso, se opôs [E-R-F]. Há, ainda, uma terceira possibilidade de interpretação do dado acima: quando o pai se manifestou contra o namoro, em algum momento queria e namorássemos foram cotemporais, encontram-se por um momento nesse intervalo de tempo. Para captar esse intervalo durativo, têm-se dois novos esquemas, desdobrados das interpretações anteriores, como seguem:

I) primeira interpretação com aspecto durativo

FIGURA 1 - Diagrama para a interpretação temporal de cotemporalidade

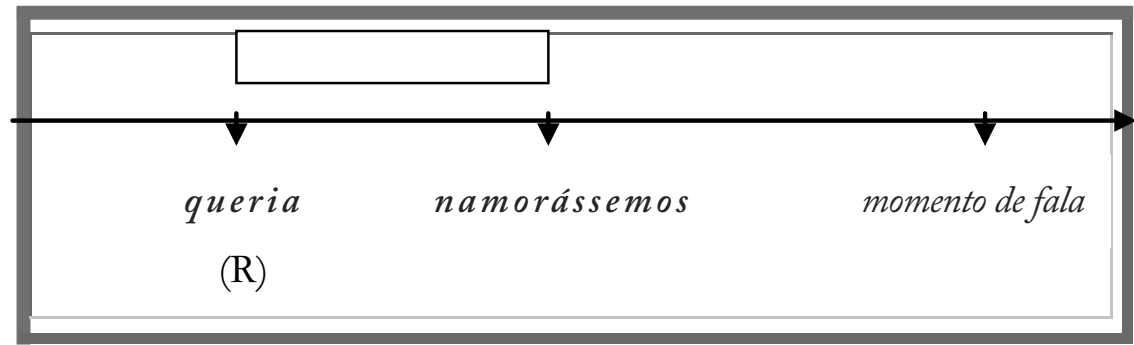

Ou

II) segunda interpretação com aspecto durativo

FIGURA 2 - Diagrama para a interpretação temporal de cotemporalidade

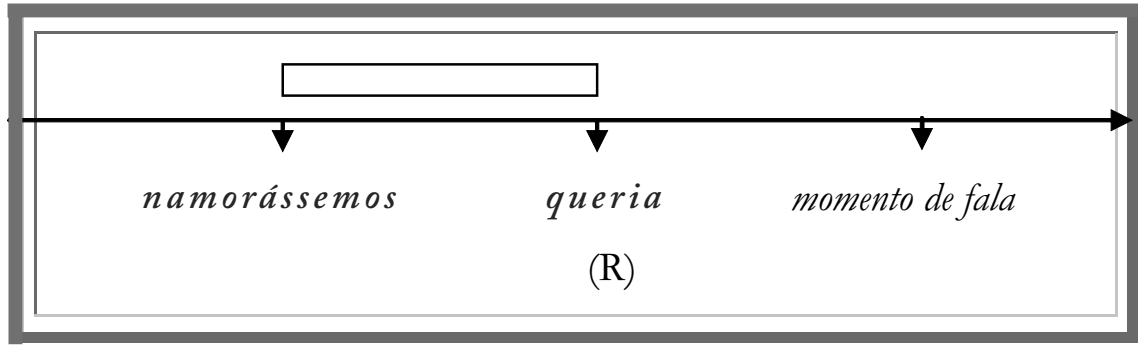


Todo o exposto tem por objetivo apontar a complexidade de (16) para cuja interpretação devemos buscar o ponto de referência além da estrutura oracional. Necessitamos, pois, de mais pistas a fim de estabelecer, com relativa segurança, as relações temporais que permeiam a situação expressa pelo PIS. A operacionalização, com base em Coan (2003), pode apontar para um ponto de referência semântico, se inserido no tópico discursivo, ou pragmático, se situado para além do contexto linguístico. Portanto, vamos ao contexto ampliado:

(16.1) $\mathrm{F}^{*}[\ldots]^{*}$ Nem perguntamos a idade um do outro. * Bom, eu com vinte e oito anos, eu me lembro eu tinha uma cara meia lisa ainda, né? (risos geral) * Mas o cabelo não! (riso geral) * O cabelo não, o cabelo era grisalho.

$\mathrm{E}^{*} \mathrm{E}$ a diferença é de quanto tempo vocês dois?

I* Dez anos, não dá bem dez anos.

$[\ldots]$

$F^{*}[\ldots .$.$] a diferencinha é poca, é quase nove anos e pouquinho.$ I* Meu pai não queria que nós NAMORÁSSEMOS, que ele_ E* Ah mas a diferença não, eu não acho que_

I* Mas só porque ele tinha jeito de ser mais velho, né? * E o pai não tinha nem cabelo branco (est) * Então o pai dizia: “* Esse aí tem idade pra ser teu pai, e não sei o que, e brigava, brigava, mas foi no fim, a gente namorou, uns oito meses eu acho, namoramos, casamos (SCCRI01, p. 08).

Diante do contexto ampliado em (16.1), a interpretação de cotemporalidade é a que fica evidenciada. Temos aí, no âmbito discursivo, um ponto de referência pretérito cotemporal ao evento sob análise.

O que acabamos de ver evidencia que, se nos limitarmos, única e exclusivamente, a esquemas temporais nos limites estruturais, sem alargamento discursivo ou contexto pragmático, a teoria de Reichenbach e nem mesmo a de outros teóricos, a exemplo de Bello, serão suficientes 
Ponto de Referência: Análise Tipológica dos Pretéritos Mais-Que Perfeito e Perfeito do Indicativo do Subjutivo

para compreender as possibilidades de expressão temporal esboçadas pelo PIS, que envolvem uma gama de relações que não se verificam em nível oracional, daí lançarmos mão da proposta de Coan (2003), readaptando-a para as situações com intensa modalização que, via de regra, remetem ao componente pragmático ou, desde que ampliado, ao semântico.

Em se tratando de pistas discursivas, é importante que se considere, como atribuidor temporal, um gradiente de explicitude discursiva do ponto de referência: estrutural (proximidade sintática), discursivo (no âmbito do tópico) e pressuposto (o gatilho até pode ser semântico, a exemplo do que propõe Coan (2003), mas também pode ser resgatado além do tópico, acionando conhecimento de mundo ou compartilhado), conforme segue.

(17) *Se nós TIVESSEMOS um país mais justo, uma renda melhor, nós não teríamos tanta gente na cadeia, assim. (SCCRI02, p. 18)

A análise é a de que o ponto de referência é pressuposto em função de ter sido desencadeado pelo 'tanta', ou seja, há muita gente presa na cadeia. Observa-se inversão de polaridade (positiva equivale à negativa ou vice-versa), o que requer por parte do interlocutor o conhecimento compartilhado dessa estratégia de inversão. Vejamos:

"Se nós tivéssemos um pais mais justo" = não temos

"náo teríamos tanta gente na cadeia" = temos muita gente

Veja que nessa inversão que equivale a "não temos um país justo" e/ ou "temos muita gente", o ponto de referência ancora-se no momento de fala, sendo, portanto, temporalmente presente.

A operacionalização do ponto de referência, para a expressão do PIS, apresentada neste trabalho, foi o fio condutor da pesquisa de Back (2008) que, após análise de 350 ocorrências de PIS, obteve uma escala que evidencia: (i) que o ponto de referência estrutural se apresenta com 
o índice de frequência mais acentuado, 67\%; (ii) que, à medida que vai sendo recuperado para além da estrutura, sua frequência diminui, 29\% para o discursivo e 4\% para o pressuposto (ora recuperado semanticamente, ora pragmaticamente). Diante disso, a autora observa que, em se tratando do PIS, o ponto de referência prototípico, considerando-se o critério da frequência, é o estrutural (temporal).

\section{Considerações finais}

Para a interpretação verbal, consideramos pontos de referência: situações de ordem semântica ou pragmática. O ponto de referência permite interpretarmos o pretérito perfeito não só como um passado em relação à enunciação, mas, também, como um passado do passado. A proposta tipológica de Coan (2003), visto tratar do eixo passado, apresenta o momento de referência como a situação que permite essa interpretação. É claro que, se deslocado o ponto de referência para o eixo futuro, outra interpretação do pretérito perfeito seria possível: a de passado do futuro, como em "Quando você chegar, eu já SAÍ'. Arroladas essas possibilidades interpretativas, mostramos como essa referência aparece no contexto. Pode ser temporal, discursiva, pressuposta (momentos semânticos) ou pragmática.

Quando aplicamos tal proposta ao imperfeito do subjuntivo, percebemos que, a depender do ponto de referência, as interpretações temporais a ele associadas são consideravelmente ampliadas. Neste trabalho, por exemplo, algumas interpretações possíveis foram discutidas: o pós-pretérito em (14) e em uma das interpretações de (16); o antepretérito em uma das interpretações de (16); o copretérito no contexto de ampliação em nível de tópico de (16); o antepretérito em (15) e, por fim, o presente em (17). Essas interpretações, portanto, decorrem, como nos casos de perfeito e mais-que-perfeito, de pontos de referência temporal, discursivo, pressuposto e pragmático, mas essas referências ganham 
componentes adicionais, a saber: o momento de referência temporal precisa ser caracterizado como modo-temporal e os tipos discursivo e pressuposto devem ser considerados com base no tópico discursivo.

Nossas considerações pretendem mostrar uma tipologia que, embora ganhe outros contornos para o caso do imperfeito do subjuntivo, é aplicável aos dados. Convém aplicá-la a outros tempos, para descobrirmos novas configurações e, então, tratar o ponto de referência como uma categoria, a exemplo de Tempo, Aspecto e Modalidade. É importante, também, que haja análise quantitativa em diversos corpora, para confirmar a hipótese de que o ponto de referência temporal é o mais frequente, por isso poderia ser considerado prototípico.

\section{Referências}

BACK, Angela Cristina Di Palma. A multifuncionalidade da forma verbal -sse no domínio Tempo-Aspecto-Modalidade: uma abordagem sincrônica. Tese (Doutorado em Linguística) - Programa de Pós-Graduação em Linguística, Universidade Federal de Santa Catarina, 2008.

. A expressão verbal a serviço do efeito de sentido metafórico. Revista de estudos linguísticos. v. 15, n. 1, 2007. p. 39-56.

BELLO, Andrés. Gramática de la lengua castellana destinada al uso de los americanos. Madrid: EDAF, 1984 (1847).

- Análisis ideológica de los tiempos de la conjugación castellana.

In: Obra literaria. Caracas: Ayacucho, 1979 (1841). p. 415-459.

COAN, Márluce. As categorias Tempo, Aspecto, Modalidade e Referência na significação dos pretéritos mais-que-perfeito e perfeito: correlação entre função(ões)-forma(s) em tempo real e aparente. Tese (Doutorado em Linguística) - Programa de PósGraduação em Linguística, Universidade Federal de Santa Catarina, 2003. 
Anterioridade a um ponto de referência passado: pretérito (mais-que-) perfeito. Dissertação (Mestrado em Linguística) - Programa de Pós-Graduação em Linguística, Universidade Federal de Santa Catarina, 1997.

COMRIE, Bernard. Tense. $4^{a}$ ed. Cambridge University Press, ([1985] 1990.

Aspect (3 ed.). Cambridge: Cambridge University Press, 1981.

DUCROT, Oswald; TODOROV, Tzvetan. Dicionário das ciências da linguagem. Lisboa: Publicações Dom Quichote, 1972. p. 365-378.

FLEISHMAN, S. The future in thought and language. New York: Cambridge University Press, 1982.

FREITAG, Raquel Meister Ko. A expressão do passado imperfectivo no português: variação/gramaticalização e mudança. Tese (Doutorado em Linguística) - Curso de Pós-graduação em Linguística, Universidade Federal de Santa Catarina, Florianópolis: UFSC, 2007.

GIVÓN, Talmy. Context as Other Minds: The Pragmatics of Sociality, Cognition and Communication. Amsterdam/Philadelphia: John Benjamins Publishing Co, 2005.

Syntax, v.I e II Amsterdam/Philadelphia: John Benjamins Publishing Co, 2001a.

- Verbal Inflections: Tense, Aspect, Modality and Negation. In: English Grammar: a functional-based introduction. v. I e II. Amsterdam/ Philadelphia: John Benjamins Publishing Co, 1993.

- Isomorphism in the grammatical code: cognitive and biological considerations. Studies in language. Amsterdam/Philadelphia: John Benjamins Publishing Co, 1991b.

A functional-typological introduction. v. 1, Amsterdam/ Philadelphia: John Benjamins Publishing Co, 1984. 
Ponto de Referência: Análise Tipológica dos Pretéritos Mais-Que Perfeito e Perfeito do Indicativo do Subjutivo

GORSKI, Edair. O tópico semântico-discursivo na narrativa oral e escrita. Tese (Doutorado em Linguística) - Programa de Pós-graduação em Letras/Linguística da Universidade Federal do Rio de Janeiro, 1994.

GRICE, H. P. Logic and conversation. In: COLE, P.; MORGAN, J.L. (Org.) Syntax and Semantics. v. 8, New York: Academic Press, 1975. p. 41-48.

IKEDA, S. N. O pretérito imperfeito: a importância da superestrutura na sua compreensão. D.E.L.T.A. v. 8, n. 1, São Paulo, EDUC, 1992.

ILARI, Rodolfo. A expressão do tempo em português: expressões da duração e da reiteração, os adjuntos que focalizam eventos, momentos estruturais na descrição dos tempos. São Paulo: Contexto, 1997.

JESPERSEN, J. O. H. The Philosophy of Grammar. New York: H. Holt, 1924.

LABOV, William. Some further steps in narrative analysis. Journal of Narrative and Life History 7, 1997. p. 395-415.

The social stratification of English in New York. Washington, D.C.: Center for Applied Linguistics, 1966.

LABOV, William; WALETZKY, J. Narrative analysis: oral versions of personal experience. (1967) In: C. PAULSTON \& G. TUCKER (eds.). Sociolinguistics - the essential readings. Oxford: Blackwell, 2003. p. 74-104.

LYONS, John. Introdução à Linguística Teórica. São Paulo: COMPANHIA EDITORA NACIONAL, 1979. . Semantics. Cambridge: Cambridge University Press, 1977. 
MATEUS, Maria Helena M. et alii A categoria linguística tempo. In: Gramática da Língua Portuguesa. Coimbra: Livraria Almedina, 1983. p. 104-153.

MATOS, Sérgio. Aspectos da semântica e pragmática do imperfeito do indicativo. Línguas e Literatura. Portugal, v. XIII, 1996. p. 435-473.

MCCAWLEY, J. Everyting that linguistics have always wanted to know about logic. Chicago: University of Chicago Press, 1993.

MOURA, Heronides Maurílio de Melo. Significação e contexto: uma introdução a questões de semântica e pragmática. Florianópolis: Insular, PGL/UFSC, 1999.

REICHENBACH, Hans. Elements of Symbolic Logic. New York: Macmillan Company, 1947.

ROJO, Guillermo y VEIGA, Alexandre. El tiempo verbal: Los tiempos simples. In: BOSQUE, Ignácio; DEMONTE, Violeta (eds.). Gramática descriptiva de la lengua española. Madrid: RAE-Espasa Calpe, 1999. Cap. 44.

SPERBER, D.; WILSON, D. Aspects of verbal communication. Relevance, Communication \& Cognition. 2. ed. Oxford: Blackwell, 1995. p. 172-254.

VAN DIJK, T. A. Contexto e Cognição. In: Cognição, Discurso e Interação. São Paulo: Contexto, 1992. 